\title{
Nitrite accumulation in an attapulgas clay biofilm reactor by fulvic acids
}

\author{
Shao-Yuan Zhang*, Ju-Si Wang, Zhao-Chun Jiang, Mei-xue Chen \\ Research Center for Eco-Environmental Sciences, Chinese Academy of Sciences, Beijing 100085, People's Republic of China \\ Received 14 October 1998; received in revised form 17 August 1999; accepted 24 August 1999
}

\begin{abstract}
As a result of seriously polluted raw water sources, some water-treatment plants in China are intending to apply the biofilm process as a pretreatment prior to the traditional drinking water-treatment systems. These polluted raw waters contain higher total organic matter and ammonium than unpolluted waters. It has been reported that synthetic organic matter can cause nitrite accumulation. However, there have been few reports about the influence of fulvic acids on nitrification. Fulvic acids are the main part of the natural organic matter in waters, and nitrite is a toxic substance which has been paid attention to recently, especially in the treatment of drinking water, so it is necessary to study the effect of fulvic acids on the nitrification process. In this experiment, a socalled 'attapulgas clay' biofilm reactor was set up, in which attapulgas clay was packed as the support medium for biological growth. After 40 days start-up, a multi-species biofilm developed in the reactor. The influence of fulvic acids on nitrite accumulation was investigated. Nitrite accumulation in the biofilm process was related to fulvic acids loadings. When the fulvic acids loading was less than $0.002 \mathrm{~kg}(\mathrm{TOC}) / \mathrm{h} \cdot \mathrm{m}^{3}$, no nitrite build-up appeared; but when the loading was in the range of $0.002-0.02 \mathrm{~kg}(\mathrm{TOC}) / \mathrm{h} \cdot \mathrm{m}^{3}, \mathrm{nitrite}$ built up and the concentration of nitrite could reach as high as $11.4 \mathrm{mg} / \mathrm{l}$. When the loading was above $0.07 \mathrm{~kg}(\mathrm{TOC}) / \mathrm{h} \cdot \mathrm{m}^{3}$, the nitrification process was completely inhibited. (c) 2000 Elsevier Science Ltd. All rights reserved.
\end{abstract}

Keywords: Biofilm reactor; Attapulgas clay; Nitrification; Fulvic acids; Nitrite; Nitrate

\section{Introduction}

Urban water demand and quality have become a world-wide problem recently. Reclaimed wastewater discharge to surface receiving bodies is considered to possibly increase water resources, but many lakes, reservoirs and rivers have eutrophication problems. The deteriorating water quality of surface water is becoming serious, especially in China, for it has less wastewater treatment than developed countries. Such a water resource background will influence the quality of raw water for drinking water. Biological treatment as a pretreatment method is one of the possible processes for polluted raw water treatment, which has some advantages such as biological stability of treatment water, reduction of chlorine demand and optimisation of the following treatments, so a biofilm system is often used as a pretreatment for drinking water to remove both or-

\footnotetext{
${ }^{*}$ Corresponding author. Present address: Environmental Biotechnology, TNO Institute, P.O. Box 342, 7300 AH, Apeldoorn, The Netherlands. Tel.: +31-55-549-3499; fax: +31-55-549-3410.

E-mail address: s.zhang@mep.tno.nl (S.-Y. Zhang).
}

ganic pollutants and ammonium from polluted raw water, and the process can be regarded as a carbonoxidation-nitrification process. Nitrite is a toxic substance, fulvic acids are the main part of natural organic matter in raw water, and have been found to inactivate exoenzymes (Wetzel, 1991). Therefore, it is necessary to study the effect of fulvic acids on nitrite build-up in nitrifying biofilm systems used for polluted raw water treatment.

\section{Methods}

\subsection{Filter system}

The Attapulgas clay biofilm reactor used was a labscale down-flow, aerated filter (BAF) as shown in Fig. 1. The reactor consisted of a plexiglass column with a $10 \mathrm{~cm}$ inside diameter. Pieces $(4 \mathrm{~mm}$ in diameter) of Attapulgas clay of density $1.67 \mathrm{~g} / \mathrm{cm}^{3}$ and which had been heated at $750^{\circ} \mathrm{C}$ for $2 \mathrm{~h}$ to enhance its mechanical strength, were packed in the reactor with a bed height of $80 \mathrm{~cm}$. The raw clay originated from Jiangsu province of 


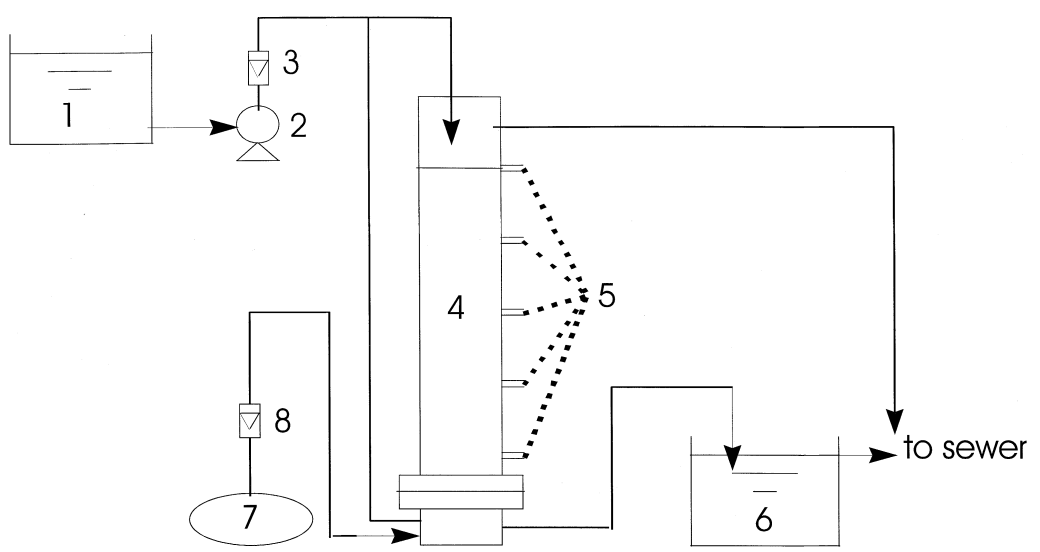

Fig. 1. Experimental set-up of a bioreactor system. 1: raw water tank; 2: feed pump; 3: liquid flowmeter; 4: bioreactor; 5: sampling ports; 6: treated water tank; 7: compressed air pump.

China, and its Chemical formula can be expressed as $\left(\mathrm{Mg}_{1.69} \mathrm{Fe}_{0.683} \mathrm{Al}_{1.351}\right)_{3.736}\left(\mathrm{Si}_{7.89} \mathrm{Al}\right)_{8} \mathrm{O}_{20}(\mathrm{OH})_{2}\left(\mathrm{OH}_{2}\right)_{4.4} \mathrm{H}_{2} \mathrm{O}$. This kind of medium has characteristics of high surface area and sorptivity (Abdrashitova, 1982; Lynwood Haden, 1967). Five sampling ports on the column were located at $0,20,40,60$ and $80 \mathrm{~cm}$ from the bottom of the medium. Feed entered from the column top at a flow rate of $6.3 \mathrm{l} / \mathrm{h}$, giving a hydraulic retention time (HRT) of $1.0 \mathrm{~h}$. Aeration at a rate of $20 \mathrm{l} / \mathrm{min}$ was also provided by a submerged diffuser in the column bottom. Temperature was maintained at $20 \pm 2^{\circ} \mathrm{C}$ during the experiment.

\subsection{Experimental procedures}

A fulvic acids solution was obtained by extracting the sediment in MiYun reservoir near Beijing, an important drinking water source for the capital, by the methods described elsewhere (Lee, 1985; Rogers, 1977). The extract had (\%): C, 33.93; H, 4.50; O, 25.5; N, 6.63 and $\mathrm{S}$, 4.14. Fulvic acids solution was concentrated further by XAD-8 resin to around $10 \mathrm{~g}$ (TOC)/l. Concentrated fulvic acids were added to tap water, which had been dechlorinated by sodium sulfite $\left(\mathrm{Na}_{2} \mathrm{SO}_{3}\right)$, to prepare artificial raw water. In addition to fulvic acids, $\mathrm{NH}_{4} \mathrm{Cl}$ was used to provide an ammonium source, whose concentration was always around $20 \mathrm{mg} / \mathrm{l}$ during the experiment.

The nitrifying seed was obtained from the nitrifying aeration tank of a local plant. Dried clay pellets were soaked in the mixed suspended liquor for 5-6 h inside the reactor, to immobilise the bacteria. The suspended liquor was replaced with fresh synthetic medium whose total organic carbon and ammonium nitrogen were 2 and $20 \mathrm{mg} / \mathrm{l}$, respectively. During the start-up process, artificial raw water continuously flowed downwards through the reactor. Every five days, the biomass on the medium was measured by standard methods. After a 40day start-up and stabilization period, biofilm was ob- served by Scanning Electron Microscope (SEM), then the fulvic acids concentration was gradually increased from 2 to $70 \mathrm{mg}$ (TOC)/1 under constant hydraulic retention time $(1 \mathrm{~h})$ to observe the effect of fulvic acids load on system performance and nitrite accumulation.

In order to run normally and to avoid clogging, washing is essential to maintain the treatment efficiency. Washing can control biomass amount in the reactor. The inactive biomass can be washed out and the biofilm layer becomes less voluminous. Treatment efficiency can on one hand deteriorate as the biomass amount is reduced, but on the other hand it can deteriorate as the biofilm layer gets too voluminous. Therefore, washing intensity should be suitable for the biofilm. The backwashing air and water flowrates were 200 and $63 \mathrm{l} / \mathrm{h}$, respectively. Backwashing was run for 20 min once a day.

\subsection{Sampling and analysis}

One week after changing the fulvic acid concentration, samples were collected and analyzed for five consecutive days. Results were compared to ensure consistency; if not within $5 \%$, the system was kept running. A $100 \mathrm{ml}$ sample was withdrawn slowly from the bottom sampling port. Samples were analyzed for $\mathrm{NH}_{4}^{+}$, $\mathrm{NO}_{2}^{-}, \mathrm{NO}_{3}^{-}$and Total Organic Carbon (TOC). Ammonium concentration was determined by a colorimetric method based on the indophenol reaction (American Pubic Health Association, 1985). Nitrite and Nitrate concentrations were determined with an Ion Chromatograph (HITACHI 655A-52 with A HITACHI L6000 Pump, A HITACHI L-37600 Conductivity Detector and A HITACHI D-2500 Chromato-integrator). TOC was determined by a Shimazu TOC analyzer (TOC-5000). Carrier samples were taken out from the sample ports for biofilm observations. Biofilm morphology was observed by SEM after treatment of the bioparticle. The quantity of the attached biomass in the 


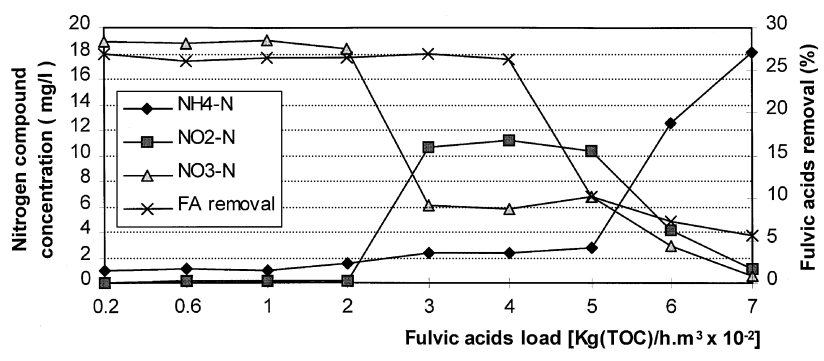

Fig. 2. Fulvic acids affecting nitrification process.

carrier was measured as ignited weight at $550^{\circ} \mathrm{C}$ according to standard methods (American Pubic Health Association, 1985). When biomass attached on the clay was measured, pieces were first washed with distilled water to remove some impurities, then dried and weighed. Unused pieces were also analysed as a blank. The dissolved oxygen (DO) was determined by a membrane electrode. DO was always more than $2.5 \mathrm{mg} / 1$ as shown by occasional DO monitoring.

\section{Results and discussion}

\subsection{Biofilm development}

Biomass at the surface of the media grew up slowly in the beginning of the bioreactor start-up, and the distribution of the biomass along the column was uneven. The biomass was mainly concentrated at the upper part of the column. From the start to day 30, biomass kept on accumulating. After day 30 the biomass amount on the surface of the media was stable and its change was less than $5 \%$, indicating that the start-up of the bioreactor had finished.

Direct observations on the biofilm of the carrier material were made and a mufti-species microbial population in the biofilm was observed. Rod-shaped bacteria constituted the major part of the biomass. Nonfilamentous bacteria predominated. Besides some metazoan genera (i.e. rotifers, nematodes), three classes of protozoa predominated the biofilm: Zoomastigophorea, Rhizopodea and Ciliata.

\subsection{Influence of fulvic acids on the nitrification process}

As shown in Fig. 2, fulvic acids load had a great influence on the performance of the nitrifying biofilm system. When the influent fulvic acids load was in the range of $0.002-0.02 \mathrm{~kg}(\mathrm{TOC}) / \mathrm{h} \cdot \mathrm{m}^{3}$, fulvic acids removal was about $27 \%$ and the ammonium, nitrite and nitrate nitrogen concentrations of the effluent were about $19,0.05$ and $1 \mathrm{mg} / 1$, respectively. At these loads no nitrite accumulated. When the influent fulvic acids concentration increased and fulvic acids load was more than $0.02 \mathrm{~kg}$ (TOC) $/ \mathrm{h} \cdot \mathrm{m}^{3}$, fulvic acids removal remained the same as before, but nitrite built up. It was clearly shown that nitrite nitrogen concentration caused by between 0.03 and $0.05 \mathrm{~kg}$ (TOC) $/ \mathrm{h} \cdot \mathrm{m}^{3}$ fulvic acids loads could reach about $11.4 \mathrm{mg} / \mathrm{l}$, the other two nitrogen compounds, ammonium and nitrate, were 2.5 and 6.0 $\mathrm{mg} / \mathrm{l}$, respectively, showing that two kinds of nitrifiers Nitrosomonas and Nitrobacter were not sensitive to inhibition by fulvic acids at the same concentration, and Nitrobacter was more sensitive to fulvic acids inhibition than Nitrosomonas. Heterotrophic bacteria were also inhibited by fulvic acids when the fulvic acids load was more than $0.04 \mathrm{~kg}$ (TOC) $/ \mathrm{h} \cdot \mathrm{m}^{3}$, which shows that heterotrophs have more ability to survive in a severe environment than autotrophs. When fulvic acids concentration went up further and the load was between 0.05 and $0.07 \mathrm{~kg}$ (TOC) $/ \mathrm{h} \cdot \mathrm{m}^{3}$, nitrification was inhibited seriously. When the load was more than $0.07 \mathrm{~kg}$ (TOC)/ $\mathrm{h} \cdot \mathrm{m}^{3}$, both nitrite and nitrate concentrations were near zero, showing that the nitrification process was completely inhibited.

\section{Acknowledgements}

The authors thank the Microbiology Institute of the Chinese Academy of Sciences for the use of their Scanning Electron Micrograph facility and their help to identify microorganism species.

\section{References}

Abdrashitova, S.A., 1982. Oxidation of three-valent arsenium by microorganisms adsorbed on inert materials.

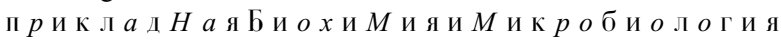
pp. 248-253.

American Pubic Health Association, 1985. Standard Methods for the Examination of Water and Wastewater, 16th ed. APHA, Washington, DC, USA

Haden, W., 1967. Attapulgite its properties and applications. Industrial and Engineering Chemistry 59 (9), 59-69.

Rogers, R.D., 1977. Abiological methylation of mercury in soil. Journal of Environmental Quality 6 (4), 463.

Wetzel, R.G., 1991. Extracellular enzymatic interactions storage redistribution and interspecific communication. In: Chrost, R.J. (Ed.), Microbial Enzymes in Aquatic Environments. Springer, New York, p. 6

Lee, Y.H., 1985. Catalytic effect of various metal ions on the methylation of mercury in the presence of humic substances. Water Air and Soil pollution 25, 391-400. 